\title{
Liquid-liquid extraction of mineral acids using Tri-n-octylamine
}

\author{
A. K. Karmakar, R. K. Biswas* and M. F. Khatun
}

Department of Applied Chemistry and Chemical Engineering, University of Rajshahi, Rajshahi-6205, Bangladesh

Received: 03 March 2019

Revised: 01 April 2019

Accepted: 06 May 2019

DOI: https://doi.org/10.3329/bjsir.v54i4.44568

\begin{abstract}
The present work reports the extraction behaviors of mineral acids: $\mathrm{HClO}_{4}, \mathrm{HNO}_{3}, \mathrm{HCl}$ and $\mathrm{H}_{2} \mathrm{SO}_{4}$ (commonly found in acidic bleed solutions from the hydrometallurgical route of metal extraction processes) by tri-n-octylamine (TOA) dissolved in distilled colorless kerosene. The systems have been investigated as functions of various experimental parameters, such as time, [acid], [TOA], temperature, extraction stage and the organic to aqueous phase volume ratio $(\mathrm{O} / \mathrm{A})$. Strippings was also examined. Equilibration time is less than $60 \mathrm{~min}$. The acid concentration in the organic phase at equilibrium is increased with increasing initial acid concentration in the aqueous phase for all systems. However, the is after \%extraction decreased with increasing initial acid concentration in the aqueous phase. The \% extraction increased remarkably with increasing [TOA] for all cases. Being the ratio of the [acid] in the organic to aqueous phase at equilibrium equal to extraction ratio, $\mathrm{D}$; the $\log$ $\mathrm{D}$ vs. $\log [\mathrm{TOA}]$ plot is almost a curve with slope 1 at lower concentration region and with slope $\sim 2$ at higher concentration region. The extraction efficiency of TOA varies in the order: $\mathrm{HClO}_{4}>\mathrm{HNO}_{3}>$ $\mathrm{HCl}>\mathrm{H}_{2} \mathrm{SO}_{4}$. The acid-base-neutralization (extraction) reactions are exothermic with $\Delta \mathrm{H}$ value much higher than $-57 \mathrm{~kJ} / \mathrm{mol}$ obtainable for of a strong acid - strong base neutralization. The loading capacity of extractant ( $\mathrm{g}$ per $100 \mathrm{~g}$ TOA) for acids varied in the order: $\mathrm{HClO}_{4}(30.69)>\mathrm{HNO}_{3}(20.49)$ $>\mathrm{H}_{2} \mathrm{SO}_{4}(17.87)>\mathrm{HCl}(10.31)$. On using lower organic to aqueous phase volume ratio $(\mathrm{O} / \mathrm{A})$, the organic phase saturated with acid can be obtained on stage-wise extraction. The extracted organic phase, for all systems (excepting $\mathrm{H}_{2} \mathrm{SO}_{4}$-system) under investigation, can be stripped effectively in a single stage by $0.10 \mathrm{~g}$ eq $/ \mathrm{L} \mathrm{NaOH}$ solution to the extents of more than $96 \%$. However, for $\mathrm{H}_{2} \mathrm{SO}_{4}$-system, two-stage stripping will be found effective.
\end{abstract}

Keywords: Mineral acid; TOA; Extraction; Stripping; Mechanism

\section{Introduction:}

Amines, categorized as an organic compounds, area derivative of ammonia and prepared by replacement of one or more hydrogen atoms by organic substituents (Biswas et al., 2017; Roose et al., 2015). Generally, they are bases of broadly varying strengths. Depending on the number of hydrogen atoms of ammonia replaced by radicals, amines are classified. The amine compounds have a lone pair of electrons on the amine nitrogen. It enables amines to contribute in a large variety of reactions as a base or a nucleophile. Amines play a prominent role in the field of extractive metallurgy (Biswas et al., 2017; Das et al., 2014; Gai et al., 2018; Hesford and McKay, 1960). The lone pair of an electron on the nitrogen atom determines the chemistry of aliphatic amines and also by the tendency of the hydrogen atoms bonded to nitrogen to be replaced by other substituents (Biswas et al., 2017; Hesford and McKay, 1960; Saw et al., 2018). Aliphatic amines are stronger bases than ammonia because they convey alkyl substituents. High molecular weight amines form salts with acids, that are less soluble in water but soluble in organic non-polar solvents. This property, combined with the difference in solubility between amine and salt, makes amines good acid acceptors and solvents for gas scrubbing and certain extraction processes. Extraction of various types of organic acids 
(e.g.1-Amino-2-Naphthol-4-Sulfonic acid (Gai et al., 2018), Acrylic acid (Tuyun and Uslu, 2015), Formic Acid (Uslu, 2009), Picric Acid (Uslu, 2011) etc.) have been studied using TOA as extractant. Fewer reports are available on the extraction of mineral acids by TOA. Hence, this extraction study has been carried out to find the extractibility and to give the mechanism of extraction. This study will provide information about the use TOA for extractions of free acids available in the acidic bleed solution of a hydrometallurgical process for environmental protection and to use $\mathrm{NaOH}$ solution for regeneration of TOA for recycling and also to obtain value-added products, such as $\mathrm{Na}_{2} \mathrm{SO}_{4}, \mathrm{NaCl}, \mathrm{NaClO}_{4}$ and $\mathrm{NaNO}_{3}$.

\section{Materials and methods}

\section{Materials}

Tri-n-octylamine was collected from Tokyo Kaie Ind. Japan $(90 \%)$. It was used without further refinement. Distilled colorless kerosene was used to dilute TOA to constitute the organic phase. All other chemicals were of reagent grade and used without further purifications. Kerosene was purchased from the local shop. It was distilled at $200-260{ }^{\circ} \mathrm{C}$ to collect colorless fraction. The requisite amount of mineral acids $\left(\mathrm{H}_{2} \mathrm{SO}_{4}, \mathrm{HCl}, \mathrm{HClO}_{4}\right.$ and $\mathrm{HNO}_{3}$ ) were dissolved separately in $250 \mathrm{~mL}$ volumetric flasks to achieve the concentration of 2.0 $\mathrm{mol} / \mathrm{L}$ for each mineral acid. In most cases, this solution was diluted to obtain test solutions for the present investigations.

\section{Analytical}

The concentration of mineral acids was determined by simple acid-base titration with standardized $\mathrm{NaOH}$ solution using 4-nitro phenol as indicator. Sometimes analyses were justified by $\mathrm{pH}$-metic titration involving standardized $\mathrm{NaOH}$ solution(Bassette et al., 1979). A Mettler Toledo (MP 220) $\mathrm{pH}$-meter was used for $\mathrm{pH}$ measurement. Wherever necessary, anhydrous $\mathrm{Na}_{2} \mathrm{CO}_{3}$ was used for $\mathrm{pH}$ adjustment of the aqueous phase.

\section{Procedure for extraction}

Except for the temperature dependence, all studies were performed at $(298 \pm 1) \mathrm{K}$ using a thermostatic water bath. Equal aliquots $(20 \mathrm{~mL})$ of aqueous and organic phases were taken in a $100 \mathrm{~mL}$ stoppered bottle and shaken well, in the thermostatic water bath. For equilibration, a predetermined time of $60 \mathrm{~min}$ was used. After equilibration, phases were settled and separated by a separating funnel. The aqueous phase was then titrated to obtain the concentration of mineral acids $\left(\mathrm{H}_{2} \mathrm{SO}_{4}, \mathrm{HCl}, \mathrm{HClO}_{4}\right.$ and $\left.\mathrm{HNO}_{3}\right)$. The distribution ratio (D) was then calculated using the following relation (superscripts ' $\mathrm{o}$ ' and ' $\mathrm{A}$ ' represent organic and aqueous phases, respectively and subscript '(ini)' and '(eq)' represent initial and equilibrium states):

$$
\begin{aligned}
\mathrm{D} & =\frac{\left(C_{(e q)}^{o}\right)}{\left(C_{(e q)}^{A}\right)} \\
& =\frac{\left(C_{(i n i)}^{A}-C_{(e q)}^{A}\right)}{\left(C_{(e q)}^{A}\right)}
\end{aligned}
$$

\section{Procedure for loading}

An aliquot of the organic phase (20 mL $0.20 \mathrm{~mol} / \mathrm{L} \mathrm{TOA})$ was repeatedly contacted for $60 \mathrm{~min}$ in each stage with a fresh aqueous solution for each mineral acid at $298 \mathrm{~K}$. After each stage, extracted acids concentrations were estimated by the titrimetric method to calculate the cumulative concentration of each mineral acid in the organic phase.

\section{Procedure for stripping}

The stripping process was virtually similar to the technique for extraction. In this case, the organic phase containing acids as solvated ion pair with TOA was equilibrated with 0.15 $\mathrm{mol} / \mathrm{L} \mathrm{NaOH}$ solution at a volume ratio $(\mathrm{O} / \mathrm{A})$ of 1 for $60 \mathrm{~min}$. On equilibration, phases were separated on settling. The aqueous phase was analyzed for acid contents. Then stripping percentage $(\mathrm{S}, \%)$ was calculated as follows:

$\mathrm{S}, \%=\frac{\left.C_{(e q)}^{A}\right) \times 100}{\left(C_{(i n i)}^{o}\right)}$

\section{Results and discussion}

In all four investigated systems, distribution of acids is completed within $30 \mathrm{~min}$. However, in subsequent experiments, shaking for $1 \mathrm{~h}$ is allowed to ensure equilibration at various experimental conditions.

\section{Effect of concentration of mineral acids on their extractions by tri-n-octylamine}

The effect of the variation of initial acid concentration on the equilibrium acid concentration in the organic phase and the percentage of extraction are shown in Table $\mathrm{I}$ for $\mathrm{H}_{2} \mathrm{SO}_{4}, \mathrm{HCl}$, $\mathrm{HNO}_{3}$ and $\mathrm{HClO}_{4}$ acid systems. In all cases, [Acid] $]_{(\mathrm{eq}, \mathrm{o})}$ increased with increasing [Acid] $]_{(\text {ini, A) }}$ as expected. In the case of sulphuric acid, the equilibrium $\mathrm{H}_{2} \mathrm{SO}_{4}$ concentration in the organic phase levels off at $\left[\mathrm{H}_{2} \mathrm{SO}_{4}\right]_{(\mathrm{ini}, \mathrm{A})}=0.13 \mathrm{~mol} / \mathrm{L}$; whence, $[\mathrm{TOA}]_{(\mathrm{ini}, \mathrm{o})}$ of $0.20 \mathrm{~mol} / \mathrm{L}$ being used. This indicates the saturation of $0.20 \mathrm{~mol} / \mathrm{L}$ TOA by $\mathrm{H}_{2} \mathrm{SO}_{4}$. In other cases, $[\text { Acid }]_{(\mathrm{eq}, \mathrm{o})}$ is increased regularly up to the studied region (no 
saturation is observed even by using initial [Acid] of $1.0 \quad$ the order: $\mathrm{H}_{2} \mathrm{SO}_{4}<\mathrm{HCl}<\mathrm{HClO}_{4}<\mathrm{HNO}_{3}$. $\mathrm{mol} / \mathrm{L}$ in the aqueous phase).

Table I. Variation of equilibrium acid concentration in the organic phase and \% extraction with initial acid concentration in the aqueous phase. $[\mathrm{TOA}]=0.20 \mathrm{~mol} / \mathrm{L}$, Equilibration time $=60 \mathrm{~min}, 0 / \mathrm{A}=1(\mathrm{O}=20 \mathrm{~mL})$, Temperature $=(298 \pm 1) \mathrm{K}$

\begin{tabular}{lllllllll}
\hline$[\mathrm{Acid}]_{(\mathrm{in}, \mathrm{A})}, \mathrm{mol} / \mathrm{L}$ & \multicolumn{5}{c}{$\%$ Extraction } \\
\cline { 2 - 9 } & $\mathrm{H}_{2} \mathrm{SO}_{4}$ & $\mathrm{HCl}$ & $\mathrm{HNO}_{3}$ & $\mathrm{HClO}_{4}$ & $\mathrm{H}_{2} \mathrm{SO}_{4}$ & $\mathrm{HCl}$ & $\mathrm{HNO}_{3}$ & $\mathrm{HClO}_{4}$ \\
\hline 0.05 & 0.050 & 0.045 & 0.048 & 0.048 & 100.0 & 90.0 & 96.0 & 96.0 \\
0.10 & 0.095 & 0.087 & 0.094 & 0.095 & 95.0 & 87.0 & 94.0 & 95.0 \\
0.15 & 0.120 & 0.138 & 0.130 & 0.125 & 80.0 & 92.0 & 86.7 & 83.3 \\
0.20 & 0.125 & 0.152 & 0.160 & 0.150 & 62.5 & 76.0 & 80.0 & 75.0 \\
0.30 & 0.130 & 0.175 & 0.190 & 0.185 & 43.3 & 56.3 & 63.3 & 61.7 \\
0.40 & 0.130 & 0.188 & 0.210 & 0.202 & 32.5 & 47.0 & 52.5 & 50.5 \\
0.50 & 0.130 & 0.194 & 0.225 & 0.212 & 26 & 38.8 & 45.0 & 42.5 \\
1.00 & 0.130 & 0.200 & 0.230 & 0.216 & 13.0 & 20.0 & 23.0 & 21.6 \\
\hline
\end{tabular}

Table II. Variation of equilibrium acid concentration the organic phase and \% extraction with initial TOA concentration in the organic phase. $[\text { Acid }]_{(\mathrm{ini}, \mathrm{A})}=\mathbf{0 . 5 0} \mathrm{mol} / \mathrm{L}$, Equilibration time $=60 \mathrm{~min}, 0 / \mathrm{A}=(\mathrm{O}=\mathbf{2 0} \mathrm{mL})$, Temperature $=(298 \pm 1) \mathrm{K}$

\begin{tabular}{lllllllll}
\hline$[\mathrm{TOA}]_{(\mathrm{ini}, \mathrm{o})}, \mathrm{mol} / \mathrm{L}$ & \multicolumn{5}{c}{ \% Extraction } \\
\cline { 2 - 9 } & $\mathrm{H}_{2} \mathrm{SO}_{4}$ & $\mathrm{HCl}$ & $\mathrm{HNO}_{3}$ & $\mathrm{HClO}_{4}$ & $\mathrm{H}_{2} \mathrm{SO}_{4}$ & $\mathrm{HCl}$ & $\mathrm{HNO}_{3}$ & $\mathrm{HClO}_{4}$ \\
\hline 0.05 & 0.033 & 0.062 & 0.080 & 0.068 & 6.6 & 12.4 & 16.0 & 13.6 \\
0.10 & 0.069 & 0.120 & 0.142 & 0.131 & 13.8 & 24.0 & 28.4 & 26.2 \\
0.15 & 0.106 & 0.159 & 0.193 & 0.180 & 21.2 & 31.8 & 38.6 & 36.0 \\
0.20 & 0.130 & 0.194 & 0.225 & 0.212 & 26.0 & 38.8 & 45.0 & 42.4 \\
0.30 & 0.193 & 0.250 & 0.284 & 0.273 & 38.6 & 50.0 & 56.8 & 54.6 \\
0.40 & 0.221 & 0.284 & 0.320 & 0.306 & 44.2 & 56.4 & 64.0 & 61.2 \\
0.50 & 0.262 & 0.333 & 0.357 & 0.353 & 52.4 & 66.6 & 71.4 & 70.6 \\
0.70 & 0.333 & 0.417 & 0.438 & 0.432 & 66.6 & 83.4 & 87.6 & 86.4 \\
1.00 & 0.409 & 0.450 & 0.465 & 0.460 & 81.8 & 90.0 & 93.0 & 92.0 \\
\hline
\end{tabular}

The percentage extraction is decreased gradually with increasing $[\text { Acid }]_{(\text {ini,A) }}$. A $100 \%$ extraction of $\mathrm{H}_{2} \mathrm{SO}_{4}$ at $\left[\mathrm{H}_{2} \mathrm{SO}_{4}\right]_{(\mathrm{ini}, \mathrm{A})}$ of $0.05 \mathrm{~mol} / \mathrm{L}$ is decreased to only $13 \%$ extraction at $\left[\mathrm{H}_{2} \mathrm{SO}_{4}\right]_{(\text {ini, o) }}$ of $1 \mathrm{~mol} / \mathrm{L}$. If acid concentration in the aqueous phase is kept low, more than $90 \%$ extraction is possible for all acids investigated. In cases of $\mathrm{HCl}, \mathrm{HNO}_{3}$ and $\mathrm{HClO}_{4}$, the $\%$ extraction at $1 \mathrm{~mol} / \mathrm{L}[\text { Acid] }]_{(\mathrm{ini}, \mathrm{A})}$ are $20 \%, 23 \%$ and $21.6 \%$. At any $[\text { Acid }]_{(\mathrm{ini}, \mathrm{A})}$, the extractability increases in
Effect of extractant concentration on the extraction of mineral acids

Table II shows the variation of equilibrium acid concentration in the organic phase with initial [TOA]. The equilibrium acid concentration and \% extraction increase with increasing initial TOA concentration in the organic phase. When initial acid concentration of $0.50 \mathrm{~mol} / \mathrm{L}$ is 
used, the $\left[\mathrm{H}_{2} \mathrm{SO}_{4}\right]_{(\mathrm{eq}, \mathrm{o})}$ increases from 0.033 (at $[\mathrm{TOA}]_{(\mathrm{ini}, \mathrm{o})}=$ $0.05 \mathrm{~mol} / \mathrm{L}$ ) to 0.409 (at $\left.[\mathrm{TOA}]_{(\mathrm{ini}, \mathrm{o})}=1.0 \mathrm{~mol} / \mathrm{L}\right)$. Similarly, $[\mathrm{HCl}]_{(\mathrm{eq}, \text { o })},\left[\mathrm{HNO}_{3}\right]_{(\mathrm{eq}, \text { o) }}$ and $\left[\mathrm{HClO}_{4}\right]_{(\mathrm{eq}, \text { o })}$ increase from 0.062 to $0.45,0.08$ to 0.465 and 0.068 to 0.465 ; respectively, for same $[\mathrm{TOA}]_{(\mathrm{ini}, \mathrm{o})}$ variation as in the case of $\mathrm{H}_{2} \mathrm{SO}_{4}$. The percentage extraction of acids also increases regularly with increase in $[\mathrm{TOA}]_{(\mathrm{ini}, \text { o) }} .6 .6 \% \mathrm{H}_{2} \mathrm{SO}_{4}, 12.4 \%$ $\mathrm{HCl}, 16 \% \mathrm{HNO}_{3}$ and $13.4 \% \mathrm{HClO}_{4}$ acid extractions at [TOA] $]_{\text {(ini, o) }}$ of $0.05 \mathrm{~mol} / \mathrm{L}$ are increased to $81.8 \% \mathrm{H}_{2} \mathrm{SO}_{4}$, $90 \% \mathrm{HCl}, 93 \% \mathrm{HNO}_{3}$ and $92 \% \mathrm{HClO}_{4}$ acid extractions at $[\mathrm{TOA}]_{(\mathrm{ini}, \mathrm{o})}$ of $1 \mathrm{~mol} / \mathrm{L}$.

The $\log \mathrm{D}$ vs. $\log \left\{[\mathrm{TOA}]_{(\mathrm{ini}, \mathrm{o})}, \mathrm{mol} / \mathrm{L}\right\}$ plots for four acid systems investigated are presented in Fig. 1. Plots are curves with asymptotic slope of $\sim 1$ at lower concentration region and of $\sim 2$ at higher concentration region. In higher concentration region i.e. in surplus of TOA, acids are solvated by two molecules of TOA; but at scarcity of extractant, acids are solvated by one molecule of TOA.
The extraction occurs via co-ordinate bond formation between amine and $\mathrm{H}^{+}$of each acid. Thus, in scarcity of extractant, the extraction reactions are:

$$
\begin{aligned}
& \mathrm{H}_{2} \mathrm{SO}_{4(\mathrm{~A})}+\mathrm{TOA}_{(0)} \rightleftharpoons\left[\mathrm{TOA} \rightarrow \mathrm{H}^{+} \mathrm{HSO}_{4}^{-}\right]_{(0)}(3) \\
& \mathrm{HX}_{(\mathrm{A})}+\mathrm{TOA}_{(0)} \rightleftharpoons\left[\mathrm{TOA} \rightarrow \mathrm{H}^{+} \mathrm{X}^{-}\right]_{(0)}(4) \\
& \text { and at surplus of extractant, the reactions are } \\
& \mathrm{H}_{2} \mathrm{SO}_{4(\mathrm{~A})}+2 \mathrm{TOA}_{(0)} \rightleftharpoons\left[\left(\mathrm{TOA} \rightarrow \mathrm{H}^{+}\right)_{2} \mathrm{SO}_{4}{ }^{2}\right]_{(0)}(5) \\
& \mathrm{HX}_{(\mathrm{A})}+2 \mathrm{TOA}_{(0)} \rightleftharpoons\left[\mathrm{TOA} \rightarrow \mathrm{H}^{-} \mathrm{X} \cdot \mathrm{TOA}_{(0)}(6)\right.
\end{aligned}
$$

Effect of temperature on the extraction of mineral acids

The vant't Hoff plots $\left(\log \mathrm{D}\right.$ vs. $\left.(1 / \mathrm{T}) \times 10^{3}, \mathrm{~K}^{-1}\right)$ are shown in Fig 2. The extraction ratio decreased with increasing temperature, and the straight-line relationship in mentioned plots holds for each system under investigation. For $\mathrm{H}_{2} \mathrm{SO}_{4}$, $\mathrm{HCl}, \mathrm{HClO}_{4}$ and $\mathrm{HNO}_{3}$ system the slopes obtained are $1.27 \times 10^{3}, 1.34 \times 10^{3}, 1.34 \times 10^{3}$ and $1.34 \times 10^{3}$, respectively. As

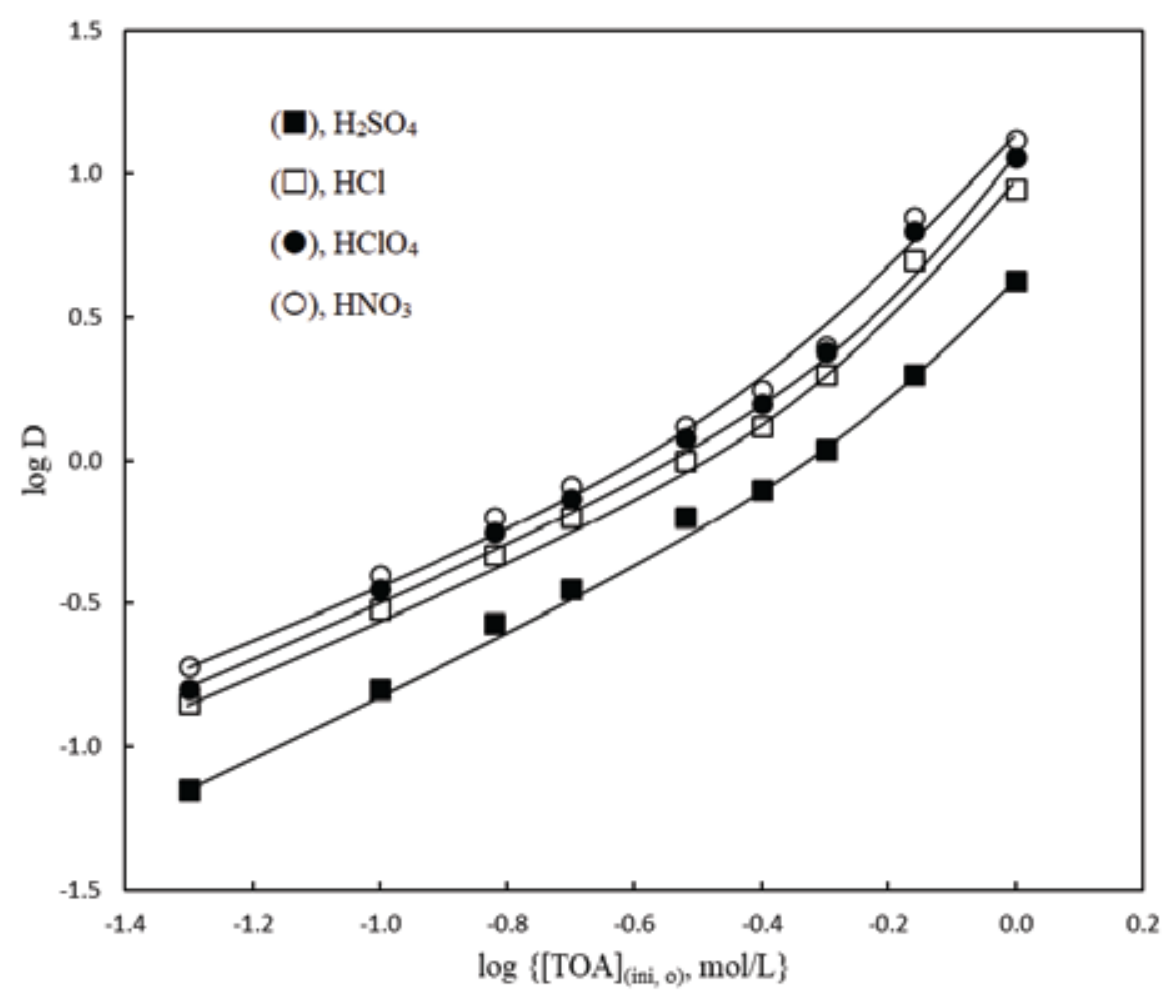

Fig. 1. Effect of extractant concentration on the extraction of mineral acids by TOA dissolved in distilled kerosene. Temperature $=303 \mathrm{~K}, \mathrm{O} / \mathrm{A}=1(\mathrm{O}=20 \mathrm{~mL})$, Equilibrium time $=60 \mathrm{~min},\left[\mathrm{H}_{2} \mathrm{SO}_{4}\right]_{(\mathrm{ini})}=0.097 \mathrm{~mol} / \mathrm{L},[\mathrm{HCl}]_{(\mathrm{ini})}=$ $0.168 \mathrm{~mol} / \mathrm{L},\left[\mathrm{HClO}_{4}\right]_{(\text {(ini) }}=0.198 \mathrm{~mol} / \mathrm{L},\left[\mathrm{HNO}_{3}\right]_{(\text {(ini) }}=0.188 \mathrm{~mol} / \mathrm{L}$ 
the slope is equal to $-\Delta H / 2.303 R$ and the values of $\Delta H$ appear for the $\mathrm{H}_{2} \mathrm{SO}_{4}, \mathrm{HCl}, \mathrm{HClO}_{4}$ and $\mathrm{HNO}_{3}$ systems as -24.32 , $-25.65,-25.65,-25.65 \mathrm{~kJ} / \mathrm{mol}$, respectively.

The acid-base neutralization $\left(\mathrm{H}^{+}+\mathrm{OH}^{-} \rightarrow \mathrm{H}_{2} \mathrm{O}\right)$ is usually exothermic with $\Delta \mathrm{H}$ value of $\sim-57 \mathrm{~kJ} / \mathrm{mol}$ for neutralization of a strong acid by a strong base. However, the neutralization for present investigated systems is Lewis type (no water being formed, instead co-ordination bond between $\mathrm{H}^{+}$and $: \mathrm{N}$ of TOA being formed). Moreover, solvation takes place at surplus of extractant and so the extraction process appears as exothermic with $\Delta \mathrm{H}$ value of $-27 \mathrm{~kJ} / \mathrm{mol}$ and not $-57 \mathrm{~kJ} / \mathrm{mol}$.
The loading result for $\mathrm{H}_{2} \mathrm{SO}_{4}$ indicates that at the saturated condition, the extraction occurs via Eq. (3) and (5). It appears that $70 \%$ extraction occurs via Eq. (5), where TOA: $\mathrm{H}_{2} \mathrm{SO}_{4}$ is $2: 1$. The rest $30 \%$ extraction occurs via Eq. (3), where $\mathrm{TOA}: \mathrm{H}_{2} \mathrm{SO}_{4}$ is $1: 1$ or $2: 2$. Therefore, overall TOA: $\mathrm{H}_{2} \mathrm{SO}_{4}$ ratio becomes $2:(1 \times 0.7+2 \times 0.3)$, i.e. $2: 1.3$ (experimentally obtained). As $1.0 \mathrm{~L}$ of $0.20 \mathrm{~mol} / \mathrm{L} \mathrm{TOA}$ can extract $0.129 \mathrm{~mol} / \mathrm{L} \mathrm{H}_{2} \mathrm{SO}_{4} ; 1.0 \mathrm{~L}$ of $1.0 \mathrm{~mol} / \mathrm{L} \mathrm{TOA}$ can extract $0.645 \mathrm{~mol} / \mathrm{L} \mathrm{H}_{2} \mathrm{SO}_{4}$. In other words, $353.67 \mathrm{~g}$ TOA can extract $0.645 \mathrm{~mol} / \mathrm{L} \mathrm{H}_{2} \mathrm{SO}_{4}$; or $100 \mathrm{~g}$ TOA can extract only $0.1824 \mathrm{~mol} / \mathrm{L} \mathrm{H}_{2} \mathrm{SO}_{4}$ i.e. $17.87 \mathrm{~g} \mathrm{H}_{2} \mathrm{SO}_{4}$.

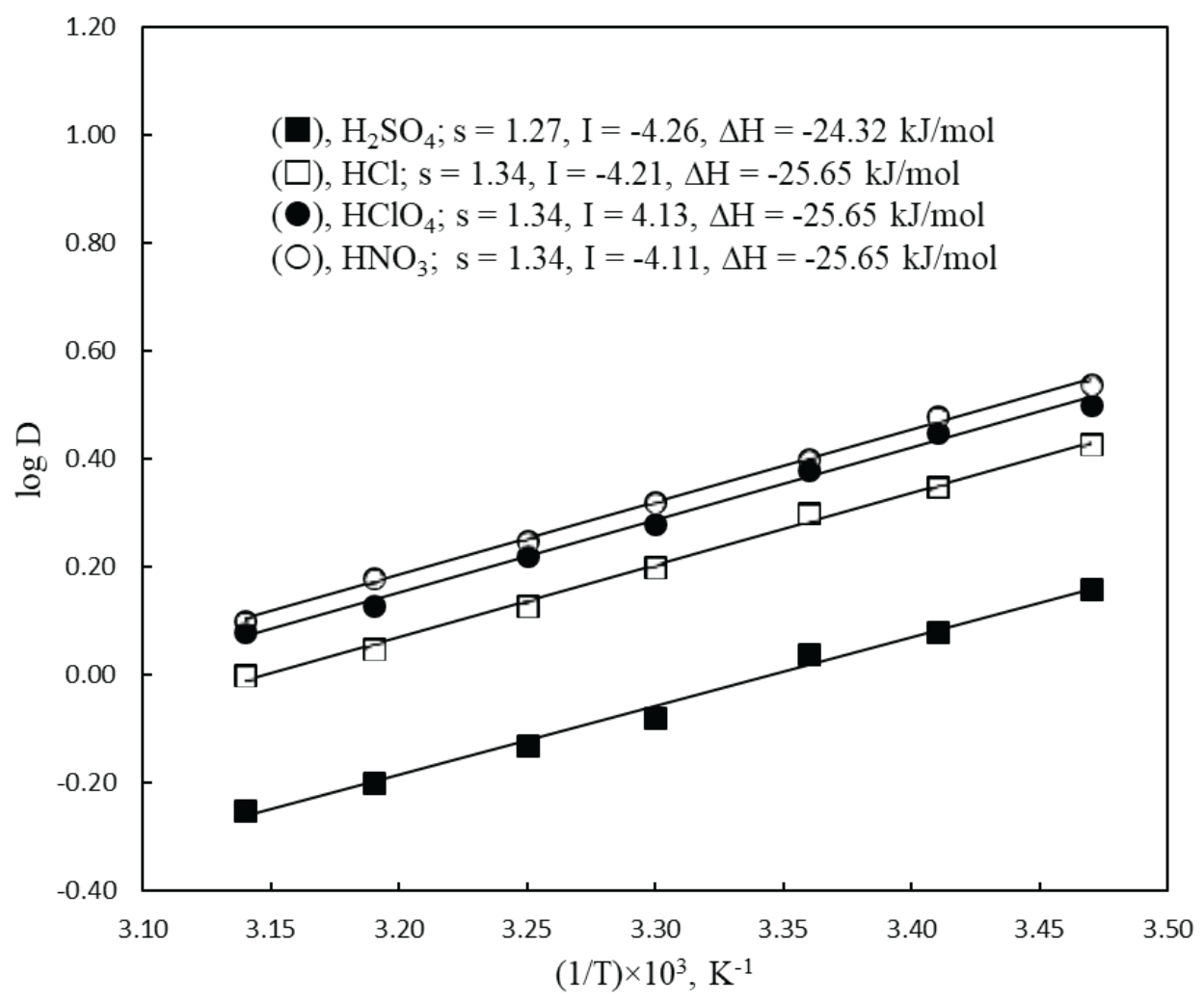

Fig. 2. Effect of temperature on the extraction of mineral acids by TOA dissolved in distilled kerosene. $\left[\mathrm{H}_{2} \mathrm{SO}_{4} \mathrm{I}_{(\mathrm{ini})}=\right.$ $0.098 \mathrm{~mol} / \mathrm{L},[\mathrm{HCl}]_{\text {(ini) }}=0.089 \mathrm{~mol} / \mathrm{L},\left[\mathrm{HClO}_{4}\right]_{(\text {ini) }}=0.102 \mathrm{~mol} / \mathrm{L},\left[\mathrm{HNO}_{3}\right]_{\text {(ini) }}=0.098 \mathrm{~mol} / \mathrm{L},[\mathrm{TOA}]=0.15 \mathrm{~mol} / \mathrm{L}$, Equilibrium time $=60 \mathrm{~min}, \mathrm{O} / \mathrm{A}=1(\mathrm{O}=20 \mathrm{~mL})$

\section{Loading of TOA solution by mineral acids}

Aqueous phase is repeatedly equilibrated with fresh extractant and each such operation is a stage. Fig. 3 represents the cumulative $[\text { acid }]_{(\mathrm{o})}, \mathrm{mol} / \mathrm{L}$ vs. stage number plot. It is observed that the organic phase is almost saturated with the mineral acids under investigation at about 4 th contact.
Therefore, the loading capacity of TOA for $\mathrm{H}_{2} \mathrm{SO}_{4}$ is $17.87 \mathrm{~g} \mathrm{H}_{2} \mathrm{SO}_{4} / 100 \mathrm{~g}$ TOA.

At saturation level, $0.20 \mathrm{~mol} / \mathrm{L}$ TOA can load $0.20 \mathrm{~mol} / \mathrm{HCl}$; so, the TOA to $\mathrm{HCl}$ ratio is $1: 1$. So, the reaction occurs via Eq. (4). If (TOA. HCl). TOA is formed initially via Eq. (6), this species extracts more $\mathrm{HCl}$ at deficiency of TOA in the system as illustrated below:

$(\mathrm{TOA} \cdot \mathrm{HCl}) \cdot \mathrm{TOA}+\mathrm{HCl} \longrightarrow 2 \mathrm{TOA} \cdot \mathrm{HCl}$ 
As $0.20 \mathrm{~mol} / \mathrm{L} \mathrm{TOA}$ solution can extract $0.20 \mathrm{~mol} / \mathrm{L} \mathrm{HCl}$ at saturation level, $353.67 \mathrm{~g}$ TOA could extract $36.45 \mathrm{~g} \mathrm{HCl}$; which is equivalent to the extraction of $10.31 \mathrm{~g} \mathrm{HCl}$ per 100 $\mathrm{g}$ TOA. In other words, the loading capacity of TOA towards $\mathrm{HCl}$ is $10.31 \mathrm{~g} \mathrm{HCl} / 100 \mathrm{~g}$ TOA in comparison to $17.87 \mathrm{~g}$ $\mathrm{H}_{2} \mathrm{SO}_{4} / 100 \mathrm{~g}$ TOA.

The cumulative $\left[\mathrm{HClO}_{4}\right]_{(\mathrm{o})}$ increases gradually with the phase contact number but levels off at the $4^{\text {th }}$ contact. $0.20 \mathrm{~mol} / \mathrm{L}$
The organic phase is almost saturated with $\mathrm{HNO}_{3}$ at the $4^{\text {th }}$ contact like in the other cases; when $0.20 \mathrm{~mol} / \mathrm{L}$ TOA solution is repeatedly contacted with fresh $0.10 \mathrm{~mol} / \mathrm{L}$ $\mathrm{HNO}_{3}$ solution at $\mathrm{O} / \mathrm{A}=1 \mathrm{in}$ each contact. It is seen that $0.20 \mathrm{~mol} / \mathrm{L}$ TOA can extract as much as $0.23 \mathrm{~mol} / \mathrm{L} \mathrm{HNO}_{3}$. This result provides the loading capacity of the extractant as $20.49 \mathrm{~g} \mathrm{HNO}_{3}$ per $100 \mathrm{~g}$ TOA.

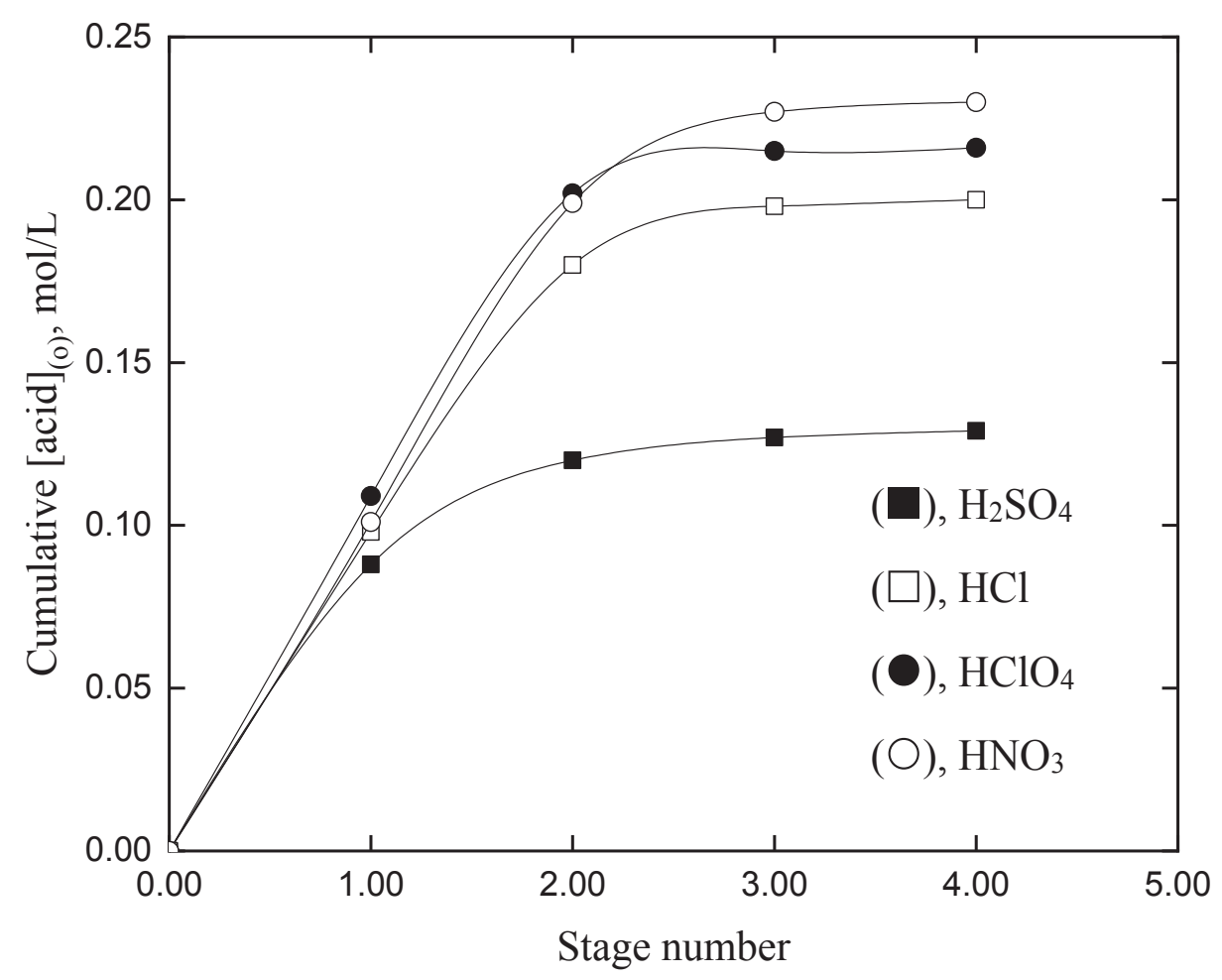

Fig. 3. Loading of TOA with mineral acids. Temperature $=303 \mathrm{~K}, \mathrm{O} / \mathrm{A}=1(\mathrm{O}=20 \mathrm{~mL})$, Equilibrium/Shaking time $=$ $60 \mathrm{~min},[\mathrm{TOA}]=0.20 \mathrm{~mol} / \mathrm{L},\left[\mathrm{H}_{2} \mathrm{SO}_{4}\right]=0.10 \mathrm{~mol} / \mathrm{L},[\mathrm{HCl}]=0.108 \mathrm{~mol} / \mathrm{L},\left[\mathrm{HClO}_{4}\right]=0.11 \mathrm{~mol} / \mathrm{L},[\mathrm{HNO}]=0.10$ $\mathrm{mol} / \mathrm{L}$ used in a stage

TOA can extract as much as $0.216 \mathrm{~mol} / \mathrm{L} \mathrm{HClO}_{4}$. This result permits to calculate the loading capacity as $30.69 \mathrm{~g} \mathrm{HClO}_{4}$ per $100 \mathrm{~g}$ TOA. Regarding weight, the loading capacity of TOA is very high for $\mathrm{HClO}_{4}$ in comparison to those for $\mathrm{H}_{2} \mathrm{SO}_{4}$ and $\mathrm{HCl}$.

Almost 1:1 mole ratio of TOA to $\mathrm{HClO}_{4}$ points out the extraction via a similar reaction as represented by Eq. (4). However, as experimental $\mathrm{HClO}_{4}$ :TOA is 1.08 , a certain portion of $\mathrm{HClO}_{4}$ is also extracted via Eq. (8):

$$
2 \mathrm{HClO}_{4}(\mathrm{~A})+\mathrm{TOA}_{(0)} \rightarrow\left(\mathrm{TOA} \rightarrow \mathrm{H}^{+}-\mathrm{ClO}_{4}+\cdots \mathrm{HClO}_{4}\right)_{(0)}
$$

As the mole ratio of TOA to $\mathrm{HNO}_{3}$ is $1 / 1.15$, in addition to reaction represented by $\mathrm{Eq}$. (4) for $\mathrm{HCl}$, the following reaction also occur in conjunction:

$$
2 \mathrm{HNO}_{3}(A)+\mathrm{TOA}_{(0)} \rightleftharpoons\left(\mathrm{TOA} \rightarrow \mathrm{H}^{+} \mathrm{NO}_{3}{ }^{-} \cdots \mathrm{HNO}_{3}\right)_{(0)}
$$

Effect of phase volume ratio (O/A) on the extraction of mineral acids

At $\mathrm{O} / \mathrm{A}=1,0.10 \mathrm{~mol} / \mathrm{L}$ TOA extracts $\sim 90 \%, \sim 83 \%, 98 \%$ and $94 \% \mathrm{H}_{2} \mathrm{SO}_{4}, \mathrm{HCl}, \mathrm{HClO}_{4}$ and $\mathrm{HNO}_{3}$, respectively. However, the $\%$ extraction at $\mathrm{O} / \mathrm{A}=0.50,0.20$ and $0.10 \mathrm{~mol} / \mathrm{L}$ TOA are 53,23 and $13 \%$ for $\mathrm{H}_{2} \mathrm{SO}_{4} ; 65,41$ and $21 \%$ for $\mathrm{HCl} ; 88,36$ 


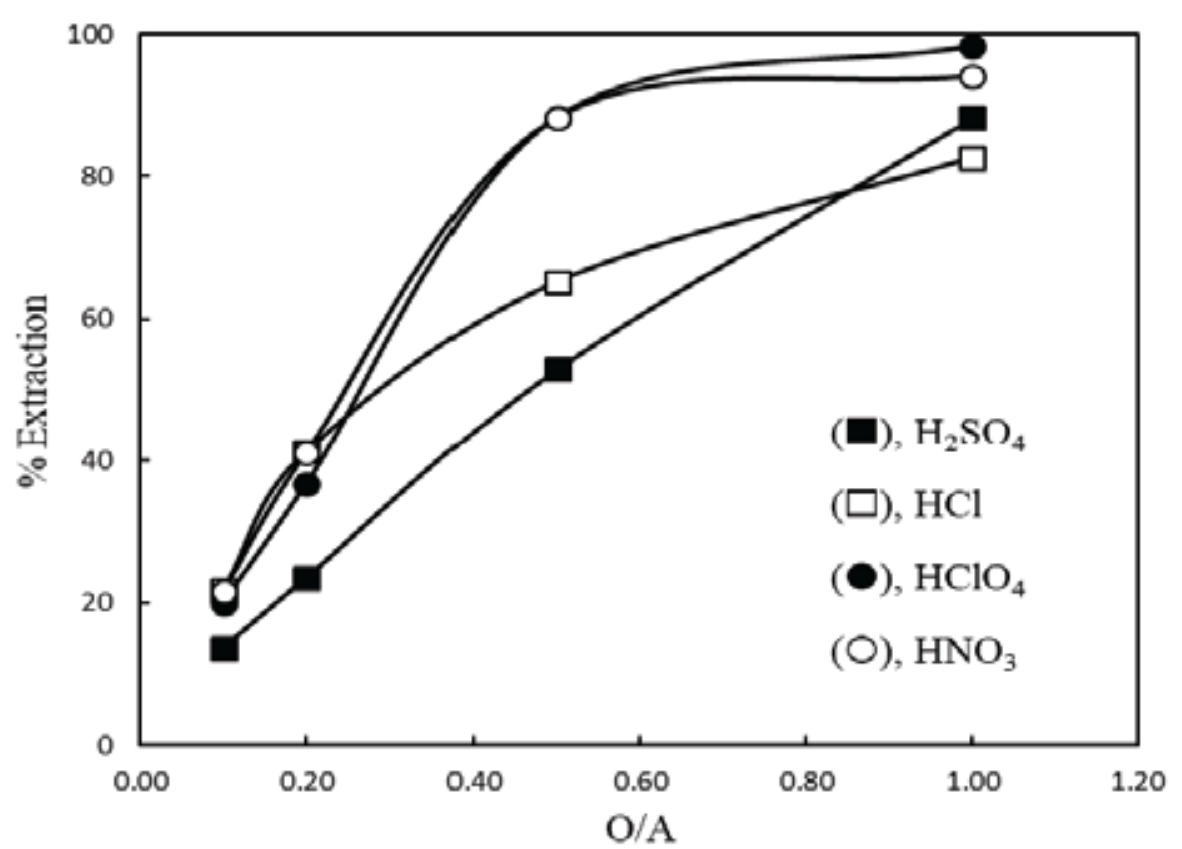

Fig. 4. Effect of volume ratio (O/A) on the percentage extraction of mineral acids by TOA dissolved in distilled kerosene. $\left[\mathrm{H}_{2} \mathrm{SO}_{4}\right]_{(\text {ini) }}=0.051 \mathrm{~mol} / \mathrm{L},[\mathrm{HCl}]_{(\text {ini) }}=0.046 \mathrm{~mol} / \mathrm{L},\left[\mathrm{HClO}_{4}\right]_{(\text {(ini) }}=0.06 \mathrm{~mol} / \mathrm{L},\left[\mathrm{HNO}_{3}\right]_{(\text {ini) }}=0.051 \mathrm{~mol} / \mathrm{L},[\mathrm{TOA}]=0.10$ $\mathrm{mol} / \mathrm{L}$, Temperature $=303 \mathrm{~K}$, Equilibration $/$ Shaking time $=60 \mathrm{~min} .0=20 \mathrm{~mL}$, A is varied as $20 \mathrm{~mL}, 40 \mathrm{~mL}$, $100 \mathrm{~mL}$ and $200 \mathrm{~mL} . \% \mathrm{Ex} .=\frac{\mathrm{D}}{\mathrm{D}+\frac{\mathrm{v}_{\mathrm{A}}}{\mathrm{v}_{\mathrm{o}}}} \times 100$

and $20 \%$ for $\mathrm{HClO}_{4}$; and 88,41 and $21 \%$ for $\mathrm{HNO}_{3}$, as shown in Fig. 4 It is realized to use lower $\mathrm{O} / \mathrm{A}$ ratio and adopt stage-wise extractions for more extraction of acids.

\section{Stripping of extracted acids}

Strippings of acids obtained in the organic phase during extractions at $\mathrm{O} / \mathrm{A}=1 / 5$ have been investigated by 0.15 mol/L NaOH solutions at $303 \mathrm{~K}$ while phase contact time of $1 \mathrm{~h}$ being allowed. The stripping results are tabulated in Table

$$
\text { TOA.HCl }{ }_{(\mathrm{o})}+\mathrm{NaOH}_{(\mathrm{a})} \longrightarrow \mathrm{TOA}_{(\mathrm{o})}+\mathrm{NaCl}_{(\mathrm{a})}+\mathrm{H}_{2} \mathrm{O}_{(\mathrm{a})}
$$

III. indicates that $\mathrm{NaOH}$ solution is a very efficient reagent to strip off $\mathrm{HCl}, \mathrm{HClO}_{4}$ and $\mathrm{HNO}_{3}$ from the organic phase. In the case of $\mathrm{H}_{2} \mathrm{SO}_{4}$ system, two-stage stripping might be required for almost quantitative regeneration of TOA. A typical stripping reaction is shown below:

On quantitative utilization of $\mathrm{NaOH}$ used in stripping, the stripped salt solutions can be evaporated to crystallize out value-added pure crystals of either $\mathrm{Na}_{2} \mathrm{SO}_{4}, \mathrm{NaCl}, \mathrm{NaClO}_{4}$ or $\mathrm{NaNO}_{3}$. On passing the stripped solution through a cation exchanger, the acids may be regenerated from these salts.

Table III. Stripping of acid-extracted organic phase by $\mathrm{NaOH}$ solution. Extraction condition: $[\text { Acid }]_{(\mathrm{ini})}=0.05 \mathrm{~mol} / \mathrm{L}$, $[\mathrm{TOA}]=0.10 \mathrm{~mol} / \mathrm{L}, \mathrm{O} / \mathrm{A}=1 / 5$, Temperature $=303 \mathrm{~K}$, Equilibration $/$ Shaking time $=60 \mathrm{~min}$. Stripping condition: $[\mathrm{NaOH}]_{(\mathrm{ini})}=0.15 \mathrm{~mol} / \mathrm{L}, \mathrm{O} / \mathrm{A}=1$, Temperature $=303 \mathrm{~K}$, Equilibration $/$ Shaking time $=60 \mathrm{~min}$

\begin{tabular}{lccc}
\hline Acid & {$[\mathrm{NaOH}]_{(\mathrm{aq}, \text { eq })}, \mathrm{mol} / \mathrm{L}$} & {$[\mathrm{NaOH}]_{(\mathrm{o}, \text { eq })}, \mathrm{mol} / \mathrm{L}$} & $\%$ Stripping \\
\hline $\mathrm{H}_{2} \mathrm{SO}_{4}$ & 0.046 & 0.104 & 86.67 \\
$\mathrm{HCl}$ & 0.056 & 0.094 & 98.95 \\
$\mathrm{HClO}_{4}$ & 0.044 & 0.106 & 96.36 \\
$\mathrm{HNO}_{3}$ & 0.046 & 0.104 & 99.04 \\
\hline
\end{tabular}


It is, therefore, recommended to extract $\mathrm{H}_{2} \mathrm{SO}_{4} / \mathrm{HCl} / \mathrm{HClO}_{4} / \mathrm{HNO}_{3}$ in the bleed solution of a hydrometallurgical process by concentrated TOA at low $\mathrm{O} / \mathrm{A}$ (if necessary stage-wise) and strip the extracted phase by a concentrated $\mathrm{NaOH}$ solution at high $\mathrm{O} / \mathrm{A}$ ratio (if necessary stage-wise) to get an aqueous solution containing highly concentrated solutions of $\mathrm{Na}_{2} \mathrm{SO}_{4} / \mathrm{NaCl} / \mathrm{NaClO}_{4} / \mathrm{NaNO}_{3}$. From these solutions, the value-added compounds can be isolated on crystallization. Therefore, the environmental protection and the isolation of value-added products are the benefits to be obtained from the hydrometallurgical acidic bleed solution as suggested from this study.

\section{Conclusion}

Following conclusions have been drawn from the system under investigation:

TOA can extract mineral acid $\left(\mathrm{H}_{2} \mathrm{SO}_{4}, \mathrm{HCl}, \mathrm{HClO}_{4}\right.$ and $\mathrm{HNO}_{3}$ ) by solvated ion pair formation mechanism.

From the extractant dependency the value of solvation number has been obtained at lower and higher concentration regions as 1 and 2 , respectively.

Temperature dependency study shows the system under investigation is exothermic. The $\Delta \mathrm{H}$ value for $\mathrm{H}_{2} \mathrm{SO}_{4}, \mathrm{HCl}$, $\mathrm{HClO}_{4}$ and $\mathrm{HNO}_{3}$ is $-24.32,-25.65,-25.65$ and $-25.65 \mathrm{~kJ} / \mathrm{mol}$, respectively.

The loading capacities of TOA for $\mathrm{H}_{2} \mathrm{SO}_{4}, \mathrm{HCl}, \mathrm{HClO}_{4}$ and $\mathrm{HNO}_{3}$ are $17.87 \mathrm{~g} \mathrm{H}_{2} \mathrm{SO}_{4} / 100 \mathrm{~g} \mathrm{TOA}, 10.31 \mathrm{~g} \mathrm{HCl} / 100 \mathrm{~g}$ TOA, $30.69 \mathrm{~g} \mathrm{HClO}_{4} / 100 \mathrm{~g}$ TOA and $20.49 \mathrm{~g} \mathrm{HNO}_{3} / 100 \mathrm{~g}$ TOA, respectively.

From the study of phase volume ratio, it is suggested to use stage-wise extractions at lower $\mathrm{O} / \mathrm{A}$ ratios.

To extract $\mathrm{H}_{2} \mathrm{SO}_{4} / \mathrm{HCl} / \mathrm{HClO}_{4} / \mathrm{HNO}_{3}$ in the bleed solution of a hydrometallurgical process by concentrated TOA at low $\mathrm{O} / \mathrm{A}$ and strip the extracted phase by a concentrated $\mathrm{NaOH}$ solution at high $\mathrm{O} / \mathrm{A}$ ratio to achieve an aqueous solution containing highly concentrated solutions of $\mathrm{Na}_{2} \mathrm{SO}_{4} / \mathrm{NaCl}$ / $\mathrm{NaClO}_{4} / \mathrm{NaNO}_{3}$ is recommended. The value-added compounds can be isolated on crystallization from these solutions. Therefore, the environmental protection and the isolation of value-added products are the benefits to be obtained from the hydrometallurgical acidic bleed solution as suggested from this study.

\section{Acknowledgement}

Mst. Fatima Khatun is thankful to the Ministry of Science and Technology, Bangladesh, for National Science and Technology Fellowship.

\section{References}

Bassette J, Denny RC, Jeffery GH and Mendham J (1979), Vogel's Textbook of Quantitative Inorganic Analysis, $4^{\text {th }}$, ELBS, London.

Biswas RK, Karmakar AK and Mottakin M (2017), Study of the Solvent Extraction of V(V) from Nitrate Medium by Tri-n-Octylamine Dissolved in Kerosene, JOM 69: 1945-1949. DOI: 10.1007/s11837-017-2470-z

Das D, Juvekar VA, Roy SB and Bhattacharya R (2014), Comparative studies on co-extraction of uranium(VI) and different mineral acid from aqueous feed solutions using TBP, TOPO and TOA, J Radioanal Nucl Chem 300: $333-343$.

Gai, H, Zhong, C, Qiao, L, Chen, S, Xiao, M and Song, H (2018), Extraction of 1-amino-2-Naphthol-4-Sulfonic acid from wastewater using trioctylamine $(\mathrm{N}$, $\mathrm{N}$-dioctyloctan-1-amine) in methyl isobutyl ketone, $J$ Cleaner Prod 201: 774-782. DOI: org/10. 1016/j.jclepro.2018.08.082

Hesford, E and McKay, HAC (1960), The extraction of mineral acids by tri-n-butyl phosphate (TBP), J Inorg Nucl Chem. 13: 156-164. DOI: org/10.1016/ 0022-1902(60)80248-5

Roose P, Eller K, Henkes E, Rossbacher R and Höke H (2015), Amines, Aliphatic In: Ullmann's Encyclopedia of Industrial Chemistry, $7^{\text {th }}$ Ed., Wiley-VCH Verlag GmbH \& Co. KGaA, Weinheim, Germany, pp 1-55. DOI: org/10.1002/ 14356007. a02_001.pub2

Saw PK, Prajapati AK and Mondal MK (2018), The extraction of $\mathrm{Cr}$ (VI) from aqueous solution with a mixture of TEA and TOA as synergic extractant by using different diluents, J Mol Liq. 269: 101-109. DOI:org/10.1016/j.molliq.2018.07.115

Tuyun AF and Uslu H (2015), Reactive extraction of acrylic acid using trioctylamine (TOA) in versatile diluents, Desalin Water Treat 55: 193-198.

Uslu, H (2009), Reactive Extraction of Formic Acid by using Tri Octyl Amine (TOA), Sep Sci Technol 44: 1784-1798.

Uslu H (2011), Separation of Picric Acid with Trioctyl Amine (TOA) Extractant in Diluents, Sep Sci Technol 46: 1178-1183. 